\title{
Analysis of Organophosphorus compound poisoning patients attending CMS-TH, Bharatpur, Nepal
}

\author{
S. Laudari ${ }^{1}$, B.S. Patowary ${ }^{2}$ \\ ${ }^{1}$ Lecturer, ${ }^{2}$ Professor of Internal Medicine, College of Medical Sciences Teaching Hospital, Bharatpur
}

\begin{abstract}
Organophosphorus (OP) compound poisoning is a medical emergency. It is important to know its nature, clinical presentation, severity and outcome in order to take up appropriate measures including proper planning, treatment and prevention. This study was aimed to assess the clinical profile of organophosphorus poisoning. This is a prospective hospital based study conducted at CMS-T.H., Bharatpur, Nepal. The study included 111 patients of organophosphorus poisoning during the period November 2008 to July 2011. The incidence was commoner in females than males with female:male ratio being 1.47:1. Majority of the patients $(58.56 \%)$ belonged to the age group 16 to 30 years with female predominance $(2.25: 1)$. Modes of poisoning were suicidal in the majority (94.59\%), accidental in 4.50\%. and homicidal in 0.90\%. Psychiatric problems were the major precipitating factors. Majority of patients $(62.16 \%)$ had moderate poisoning (POP scale: 4-7).On admission, dyselectrolytemia and respiratory failure were found in $74.77 \%$ and $21.62 \%$ respectively. 8 patients expired $(7.69 \%)$. Large amount of OP poison ingestion $(>40 \mathrm{ml})$ and increased severity of poisoning (POP scale) were found to have statistical significance with the rate of mortality.
\end{abstract}

Keywords: OP poisoning, severity and outcome, hospital care.

\section{Introduction}

Organophosphorus compounds (OP) account for as much as $80 \%$ of pesticide-related hospital admissions. ${ }^{1}$ OP pesticide intoxications are estimated at 3 million per year worldwide with approximately 300,000 deaths. $^{2}$ About $60 \%$ of estimated deaths from self-harm in the Asia each year are due to pesticide poisoning and organophosphorus pesticides are responsible for around two-thirds of these deaths - a total of 200,000 a year ${ }^{1,3}$. Worldwide mortality studies

Correspondence: S. Laudari

E-mail: 1shankar2@hotmail.com report mortality rates from $3-25 \%^{1,4}$. The compounds most frequently involved include malathion, dichlorvos, methylparathion and fenitrothion.

Nepal is an agricultural country. It is important to save the crops from pests, fungi etc using chemical compounds. Hence, there is a large market for OP products which are very easily available, highly potent and lethal to insects as well as humans. Poisoning with organophosphate compounds is getting more common and it is highly lethal if not 
timely managed. Death occurs within 24 hours if untreated, mostly due to respiratory failure ${ }^{2,4}$.

\section{Materials and methods}

This is a prospective study of 111 patients attending the Emergency Services at CMS-Teaching Hospital during a period of 32 months from November 2008 to July 2011 with history or clinical features suggestive of organophosphorus poisoning. The severity of OP poisoning was assessed as per Peredeniya Organophosphate Poisoning Scale ${ }^{5}$ (POP scale). Psychiatric assessment was done by expert psychiatrist consultation. The data collected using the proforma was entered in the computer in data base and statistical analysis was done using SPSS version 16. Chi Square test was done and $\mathrm{p}<0.05$ was considered significant.

\section{Results}

The youngest victim was 1 year old and the eldest was 75 years with $66(59.50 \%)$ females and $45(40.50 \%)$ males, the ratio of female: male being 1.47:1. Majority of the patients 65 (58.56\%) belonged to the age group 16-30years in which females were $45(69.23 \%)$ and males were 20 $(30.77 \%)$ with female: male ratio $=2.25: 1$.

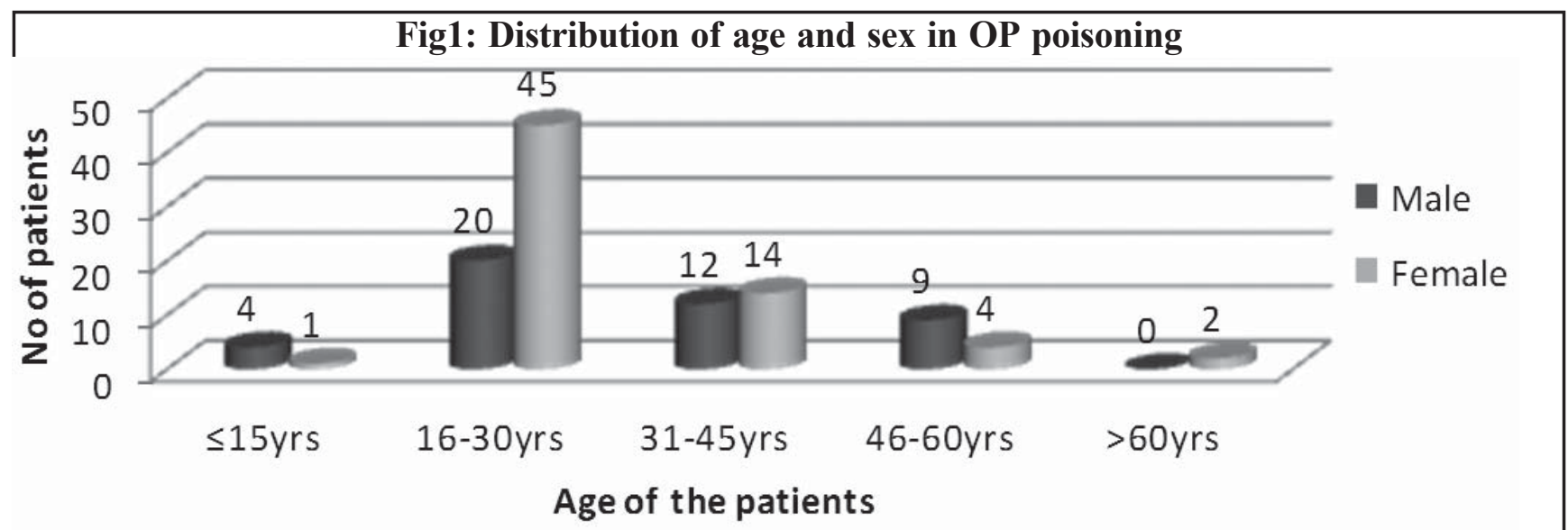

Modes of poisoning were intentional- suicidal in the majority $105(94.59 \%)$ and homicidal in $1(0.90 \%)$ while 5 patients $(4.50 \%)$ had accidental consumption.

\section{Lag time period from taking of OP poison and} arrival at the hospital $(n=111)$

44 patients arrived d" 2 hours, 54 patients at $>2$ 6hours and 13 patients arrived at $>$ 6hours.

The amount of OP poison ingested ranged from $3 \mathrm{ml}$ to $250 \mathrm{ml}$.

Severity of OP poisoning by POP scale $(n=111)$

37 patients had mild poisoning, 69 had moderate poisoning and 5 had severe poisoning as per POP scale.
Precipitating factors were analysed in all the patients attempting suicide $(\mathrm{n}=105)$.

It was found that varying psychiatric illnesses were present in the majority $(82 / 105=78.09 \%)$ with depression in most $(67=63.80 \%)$ of them. Household conflict was very common $(90=85.71 \%)$. Alcohol abuse was associated in 46(41.44\%). Major groups of population affected were farmers $(49=46.67 \%)$, housewives $(47=44.76 \%)$ and students $(32=30.47 \%)$. Easy availability of poisons, mostly remaining stored at home was instrumental in the suicidal attempts in 96(91.43\%) patients. It was observed that there was frequent overlapping of the precipitating factors in most of them. 
S. Laudari et al, Analysis of Organophosphorus compound poisoning.

\section{Clinical features of Organophosphorus} poisoning at presentation $(n=111)$

At the time of presentation, muscarinic effects were observed in 108(97.29\%) patients, nicotinic effects in $26(23.42 \%)$ and central effects in $103(92.79 \%)$ patients.

Most of the patients(92 no.) had excessive salivation and sweating,agitation and vomitting (70

Complications of OP compound poisoning $(n=111)$

A. At presentation no.),tachypnoea(76 no.), respiratory failure(24 no.) with Spo $2<90 \%$ (10 no.), tachycardia (57 no.) with ventricular ectopics( 2 no.), low BP (7 no.) and HTN in 21 patients, pupils- miosis(82no.) and mid-dilated 32 , GCS $<13$ in 53 patients, fasciculations in 15pts., convulsion(16 no.), flaccid paralysis(24 no.), plantar reflexes being extensor in 38 and mute in 13 pts. Deep tendon reflexes showed brisk response in 17 with hyporeflexia in 23 patients.
Seizure

Pulmonary edema

Respiratory failure

Aspiration pneumonia

Dyselectrolytemia

-Hyponatremia $(<135 \mathrm{meq} / \mathrm{l})$

-Hypernatremia $(>145 \mathrm{meq} / \mathrm{l})$

-Hypokalemia $(<3.5 \mathrm{meq} / \mathrm{l})$

-Hyperkalemia $(>5.5 \mathrm{meq} / \mathrm{l})$

Acute kidney injury

Acid base disturbances

-Metabolic acidosis

-Mixed acidosis

-Respiratory acidosis

\begin{tabular}{cc} 
Number & Percentage \\
\hline 16 & 14.41 \\
24 & 12.61 \\
24 & 21.62 \\
6 & 5.40 \\
$\mathbf{8 3}$ & $\mathbf{7 4 . 4 4}$ \\
27 & 24.32 \\
9 & 8.11 \\
46 & 41.44 \\
1 & 0.90 \\
18 & 16.22 \\
$\mathbf{1 6}$ & $\mathbf{1 4 . 4 1}$ \\
8 & 7.21 \\
5 & 4.50 \\
3 & 2.70 \\
& \\
7 & 6.31 \\
21 & 18.92 \\
2 & 1.80 \\
24 & 21.62
\end{tabular}

Blood pressure

-Hypotension

-Hypertension (Accelerated BP: $\leq 180 / 110 \mathrm{mmHg}$ )

Arrhythmias (Ventricular ectopics)

Acute gastritis

Aspiration pneumonia

Tachycardia

Urinary retention

Intermediate syndrome

Delayed neuropathy

Guillain Barre Syndrome like picture

0

0.00 


\section{Treatment}

i. Gastric lavage with activated charcoal was done in 106/111(95.49\%) patients. All the patients tolerated well. Decontamination was done to all the patients.

\section{ii. Antidotes used}

a. Atropine: All the patients were atropinised soon after arrival.1.8-3 mg atropine was given iv bolus immediately followed by doubling of the dose every 5 minutes until full atropinisation occured as evidenced by dry secretions, dilated pupils and tachycardia (pulse rate about 110-120/minute).Once patient was atropinised,20-30\% of the total atropinisation dose was calculated and maintained as intravenous infusion per hour, continued for 2 to 3 days maintaining the full atropinisation, thereafter the infusion dose was daily reduced by $1 / 4^{\text {th }}$ to $1 / 3^{\text {rd }}$ of the previous day's dose.

Atropinisation dose varied from $0.6-84 \mathrm{mg}$. Total atropine used ranged from 7.2$1907 \mathrm{mg}$ in iv infusion. Total days of atropine administered varied from 1-16days. Majority of the patients (43.24\%) required mild amount (upto100mg) of total atropine dosing for their treatment. However, $6(5.40 \%)$ patients required very high amount of total atropine $(>1000 \mathrm{mg})$. Maximum dose of atropine administered was $1907 \mathrm{mg}$.

Side effects/toxicity of atropine observed were- psychosis in 72 (64.86\%)patients, tachycardia in 57(51.35\%) and urinary retention in $42(37.84 \%)$ patients. b. Pralidoxime (PAM): Initial loading dose @ $30 \mathrm{mg} / \mathrm{kg}$ body weight iv followed by maintenance dose @ $8 \mathrm{mg} / \mathrm{kg} / \mathrm{hr}$ in iv infusion. The total dose of PAM required ranged from $4-48 \mathrm{gm}$ and the duration of PAM administration was 1-8 days. Side effect/ toxicity of PAM observed was none $(0 \%)$.

c. Symptomatic treatment eg. iv fluid infusion, administration of antibiotics, anticonvulsants, urinary bladder catheterization etc as necessary.

The duration of hospital stay ranged between 118 days, mean stay being 7.24days.

Majority of the patients 71 in no.(63.96\%) were admitted in ICU for close monitoring and early intervention for anticipated complications as required. $24(21.62 \%)$ of them with respiratory failure were endotracheally intubated and connected to Bain Circuit or mechanical ventilator as required. Out of those intubated patients, $8(33.33 \%)$ expired, $7(29.17 \%)$ were taken on LAMA and the rest $9(37.50 \%)$ survived.

\section{Outcome of the patients (pts.) $(n=111)$}

A. i. $\quad 7$ patients(6.31\%) left against medical advice(LAMA).

ii. Of remaining 104 patients-

a. Discharged after recovery:96(92.31\%)

b. Expired:8 (7.69\%)

The causes of death were respiratory failure in $3(2.70 \%)$, pulmonary edema/aspiration pneumonia in $4(3.60 \%)$ and seizure/status epilepticus in $1(0.90 \%)$. 
S. Laudari et al, Analysis of Organophosphorus compound poisoning.

B. Outcome of patients in relation to the lag time interval $(n=111)$

\begin{tabular}{lcccc}
\hline Lag time in hrs & LAMA pts. & $\begin{array}{c}\text { Total pts. } \\
\text { remaining }\end{array}$ & $\begin{array}{c}\text { Recovery } \\
\text { (out of 104 pts.) }\end{array}$ & $\begin{array}{c}\text { Mortality } \\
\text { (out of 104 pts.) }\end{array}$ \\
\hline$\leq 2$ & $0(0.00 \%)$ & $44(42.31 \%)$ & $40(38.46 \%)$ & $4(3.85 \%)$ \\
$>2-6$ & $5(4.50 \%)$ & $49(47.11 \%)$ & $46(44.23 \%)$ & $3(2.88 \%)$ \\
$>6$ & $2(1.80 \%)$ & $11(10.57 \%)$ & $10(9.61 \%)$ & $1(0.96 \%)$ \\
\hline Total & $\mathbf{7 ( 6 . 3 1 \% )}$ & $\mathbf{1 0 4 ( 1 0 0 \% )}$ & $\mathbf{9 6 ( 9 2 . 3 0 \% )}$ & $\mathbf{8 ( 7 . 6 9 \% )}$ \\
\hline
\end{tabular}

It was observed that the mortality rate did not really vary with respect to the variation in the lag time of hospitalization.

C. Outcome in relation to the amount of OP poison intake $(n=111)$

\begin{tabular}{lcccccc}
\hline $\begin{array}{l}\text { Amount of poison } \\
\text { (in } \mathbf{~ m l ) ~ i n g e s t e d ~}\end{array}$ & No. & $\mathbf{\%}$ & No. & remaining & No. & \% \\
\hline$<40 \mathrm{ml}$ & 85 & 76.58 & 3 & $82(78.84 \%)$ & 2 & 2.44 \\
$>40 \mathrm{ml}$ & 26 & 23.42 & 4 & $22(21.15 \%)$ & 6 & 27.27 \\
\hline Total & $\mathbf{1 1 1}$ & $\mathbf{1 0 0 . 0 0}$ & $\mathbf{7}$ & $\mathbf{1 0 4}(\mathbf{1 0 0 . 0 0 \% )}$ & $\mathbf{8}$ & $\mathbf{7 . 6 9}$ \\
\hline
\end{tabular}

Of 22 patients consuming $>40 \mathrm{ml}$ of OP poison, there were $6(27.27 \%)$ mortalities as compared to 2 of 82 patients $(2.44 \%)$ consuming $<40 \mathrm{ml}$ poison- this difference was found to be statistically significant $(\mathrm{p}<0.02)$.

D. Outcome of the patients in relation to the severity of poisoning(POP scale)(n=111)

\begin{tabular}{lcccc}
\hline POP scale & Total pts. & Patients on LAMA & No of pts. remaining & Mortality \\
\hline Mild & 37 & 1 & 36 & $0(0.00 \%)$ \\
Moderate & 69 & 6 & 63 & $7(11.11 \%)$ \\
Severe & 5 & 0 & 5 & $1(20.00 \%)$ \\
\hline On admission & $\mathbf{1 1 1}$ & $\mathbf{7}$ & $\mathbf{1 0 4}$ & $\mathbf{8}(\mathbf{7 . 6 9 \% )}$ \\
\hline
\end{tabular}

The increase in the severity of poisoning by POP scale has been observed to have statistical significance with the rise in mortality $(p=0.04)$. 


\section{Discussion}

The age of the patients in the present study ranged from 1-75years which is similar (1-70years) and (1-68years) to that reported from AIIMS (Srivastava et $\left.\mathrm{al}^{6}, 2005\right)$ and Karnataka (Kiran et $\mathrm{al}^{7}, 2008$ ) respectively. In another study from Bir Hospital(Nepal) by DP Singh and Acharya ${ }^{8}$ (2006), the age of the patients ranged from 16 to 65 years.

The present study showed preponderance of females $(59.50 \%)$ as compared to males $(40.50 \%)$, the ratio being (1.47:1). A similar trend was observed in India ${ }^{9}$, Bangladesh ${ }^{10}$, Pakistan ${ }^{11}$, Srilanka ${ }^{12}$, Turkey ${ }^{13}$ and $\mathrm{Nepal}^{14}{ }^{14}(52.6 \%$ females and $47.4 \%$ males, the ratio being 1.1:1 from $\mathrm{BDH}$, Bharatpur by Ghimire et al, 2004). However, male preponderance has also been reported by some authors viz. Ramesha et $\mathrm{a}^{15}$ from Karnataka, India (3.1:1), Kiran et $\mathrm{al}^{16}(1.7: 1)$ from South India and Srivastav et $\mathrm{al}^{6}(2005)$ from AIIMS, India (57.0\%).

In the present study, the age group 16-30yrs $(58.56 \%)$ has been found to be the most vulnerable for self-poisoning with female predominance $(45$ of $65=69.23 \%$ ). Similar observations of prevalence of patients in the age group 16-25 years(both) with female preponderance of $76.8 \%$ and $67.34 \%$ respectively has been reported from Nepal by DP $\operatorname{Singh}(2005)^{8}$ and Ghimire et $\mathrm{al}^{14}$. Anjum et $\mathrm{al}^{20}$ from India reported $53.25 \%$ belonging to 20 $30 y e a r s$ age group with female predominance.

The high incidence of female preponderance found in the present study may probably be due to increase stress and strain in day to day life in this society added with family disputes, less financial and social support from the family, marital dysharmony and more occupational exposure as compared to the males.
Attempted suicide has been found to be the most common cause $(87.33 \%)$ of poisoning in the present study. Similar patterns have been reported from India viz. ( $91.4 \%$ by Siwach and Gupta ${ }^{24}, 1995$ and $87.54 \%$ by Anjum et $\mathrm{al}^{20}, 2009$ ); Bangladesh (83.62\% by Rahman $\left.{ }^{25}, 2000\right)$; Pakistan $(78 \%$ by Suliman et $\left.\mathrm{al}^{26}, 2006\right)$; SriLanka (75\% by Alwis ${ }^{27}$, $1988)$ and other parts in Nepal $\left(58.2 \%\right.$ by Khadka ${ }^{21}$, 2005, 66.22\% by Thapa et $\mathrm{al}^{28}, 2008$ and $79.24 \%$ by Marahatta et $\left.\mathrm{al}^{29}, 2009\right)$.

The lag time arrival at hospital after exposure to poison was within 2 hours in $44.70 \%$ patients, although majority $(85.3 \%)$ had arrived within 6 hours after exposure. Higher incidence of patients presenting within 2 hours of ingestion of the poison was reported by Karki et al ${ }^{22}$ from Dharan(90\%) and $55 \%$ by Srinivas $\mathrm{RaO}^{23}$ from MGM hospital (India,2005). Lag time interval of 3 hours has been reported in $61.6 \%$ patients by DP Singh et $\mathrm{al}^{8}$ (2006) from Bir Hospital, Nepal.

In our study,37(33.3\%) patients had mild poisoning,69(62.2\%) had moderate poisoning and $5(4.5 \%)$ had severe poisoning as per POP scale. Rehiman et $\mathrm{al}^{30}$ (2008) from Bir Hospital reported the majority (70\%) with mild poisoning followed by $26 \%$ (moderate) and $4 \%$ (severe) as per POP scale. Shaikh et al ${ }^{31}(2008)$ reported $64(57.7 \%)$ of mild, $30(27.0 \%)$ of moderate and $17(15.3 \%)$ of severe OP poisoning.

The analysis of precipitating factors leading to suicidal attempts in 105 patients in the present study revealed that psychiatric illness $(78.09 \%)$, mostly depression $(52.67 \%)$ was the major factor of suicidal tendencies.Quarreling with family members was very common $(85.71 \%)$. Alcohol abuse was associated in $41.44 \%$. There was 
S. Laudari et al, Analysis of Organophosphorus compound poisoning.

frequent overlapping of these precipitating factors in most of the patients. Attempted suicide was observed more among farmers (46.67\%) followed by housewives( $44.76 \%)$ and students( $30.47 \%)$. The study from Dhulikhel ${ }^{29}(2009)$ showed that $37.04 \%$ of the cases consumed poison due to quarrel in the family, $11.12 \%$ due to financial crisis and $24.08 \%$ due to failure in examination. $40.74 \%$ of the respondents constituted farmers, $31.49 \%$ housewives and $16.67 \%$ were students.Kiran et al ${ }^{16}$ from South India (St Martha's Hospital,2008) reported that the majority $(57.43 \%)$ were married individuals which corresponds to the findings of the present study $(74 / 105=70.47 \%)$ which suggests some degree of marital dysharmony as an underlying cause.

At the time of presentation, muscarinic effects were observed in 108(97.29\%) patients, nicotinic effects in 26(23.42\%) and central effects in 103(92.79\%) patients. Suliman et $\mathrm{al}^{26}(2006)$ from Pakistan(Faisalabad) in a series of 143 patients reported muscarinic effects in $140(98 \%)$, nicotinic in $3(2 \%)$ and central effects in $130(91 \%)$.

The common complications observed at presentation were dyselectrolytemia in the majority $(74.77 \%)$, followed by respiratory failure( $21.62 \%)$,seizure( $14.41 \%)$ and pulmonary edema(12.61\%).Suliman et $\mathrm{al}^{26}(2006)$ reported respiratory failure/aspiration pneumonia in $5(3.5 \%)$, circulatory collapse in $1(0.7 \%)$ and seizure in $2(1.4 \%)$.

During hospital stay, $3(2.70 \%)$ developed respiratory failure with neck and proximal muscle weakness (intermediate syndrome).Wadia RS et al ${ }^{32}$ from Sassoon General Hospital(1974) reported $36(18 \%)$ of Type 2(intermediate syndrome) cases in their series of 200 patients. Karki et $\mathrm{a}^{22}$ from BPKIHS(2001) reported 2 cases(5.4\%) of IMS in their series of 37 patients. Avasti $\operatorname{Singh}^{33}(2000)$ and Jayawardane et $\mathrm{al}^{34}(2008)$ reported variable incidence of $\operatorname{IMS}(19 / 29=65.55 \%$ and $10 /$ $78=12.82 \%$ respectively).

\section{Treatment}

Gastric lavage with activated charcoal was done in 106/111(95.49\%) patients. Eddleston $\mathrm{M}^{35}$ (2008) reported that 97 (6.3\%) of 1531 participants in the multiple-dose activated charcoal group died, compared with $105(6 \cdot 8 \%)$ of 1554 in the no charcoal group (adjusted odds ratio $0.96,95 \% \mathrm{CI}$ $0 \cdot 70-1 \cdot 33$ ) and presumed that early charcoal administration might be useful but the routine use of multiple dose activated charcoal in rural Asia Pacific was not recommended.

The mean dose of atropine used was $356.25 \mathrm{mg}$. Majority of the patients (43.24\%) required mild amount (upto100mg) of total atropine dosing for their treatment. However, $6(5.40 \%)$ patients required very high amount of total atropine $(>1000 \mathrm{mg})$. Maximum dose of atropine administered was $1907 \mathrm{mg}$. Karalliedde and Senanayeke ${ }^{36}(1989)$ reported mean atropine dose of $969 \mathrm{mg}$ with maximum dose being 1300mg.Study from BPKIHS'22(2001) showed that the mean dose of atropine required during hospital stay was $136.7 \mathrm{mg}$.

In our study, the total dose of PAM required ranged from 4-48gm with mean dose of $24.22 \mathrm{gm}$ and the duration of PAM administration was 1-8 days. Suliman et $\mathrm{al}^{26}(2006)$ reportd a higher mean dose of PAM(54gm \pm 41.6$)$ required and the duration of 
its administration being 1-8 days. The Cochrane review (Eddleston $\mathrm{M}$ et $\mathrm{al}^{35}$,2002) included two randomised controlled trials and reported no clear evidence of benefit or harm.

The hospital stay of the patients in this series ranged from 1-18 days, mean being 7.24 days which is similar to 1-16 days with mean hospital stay being 5.9 days as reported by DP Singh and Acharya $^{8}(2006)$ and 7.9 days in the series of Kiran et $\mathrm{al}^{16}(2008)$. Analysis of retrospective data (256 cases) collected from five major hospitals of Nepal by Gupta and Joshi ${ }^{37}$ (2002) revealed that the hospital stay varied from 1-27days, mean being 8.2 days.

Majority of the patients 71 in no.(63.96\%) were admitted in ICU out of whom 24 with respiratory failure $(21.62 \%)$ were endotracheally intubated and connected to Bain Circuit/Mechanical ventilator. Of these 24 patients, $8(33.33 \%)$ expired, $7(29.17 \%)$ were taken on LAMA and the rest $9(37.50 \%)$ survived of whom 3 had IMS. Goswamy et al ${ }^{38}$ (1994) reported that mechanical ventilation was required in 31 subjects $(59.62 \%)$ out of 52 OP poisoning patients;33 patients(63.46\%) survived. Shaikh et $\mathrm{al}^{31}(2008)$ reported the commonest complications during ICU stay due to respiratory failure(18\%) followed by $\operatorname{IMS}(4.5 \%)$, $\operatorname{ARDS}(8.1 \%)$, sepsis and MODS(4.5\%) and delayed polyneuropathy $(0.9 \%)$.

The overall outcome of the patients with poisoningi.7 patients $(6.31 \%)$ left against medical advice(LAMA) ii.Of remaining 104 patients a. discharged after recovery:96(92.31\%)b. expired:8(7.69\%).Variable mortality rates have been reported from other parts of Nepal-24.48\% from Bir Hospital; $13.89 \%$ from BPKIHS; $16.67 \%$ from Patan Hospital;20\% from TUTH;3.45\% from WRH, Pokhara (Gupta and Joshi ${ }^{37}, 2002$ ) and 3.3\% from Ghimire et $\mathrm{al}^{14}$ from Bharatpur during 20002002. Karki et $\mathrm{al}^{22}$ (2001), Pathak et $\mathrm{al}^{21}$ (2001) and Rehiman et al ${ }^{30}$ reported an overall mortality of $8 \%$, $6 \%$ and $14 \%$ respectively due to OP poisoning.

The causes of death were respiratory failure in $3(2.70 \%)$, pulmonary edema/aspiration pneumonia in $4(3.60 \%)$ and seizure/status epilepticus in $1(0.90 \%)$.Rehiman et $\mathrm{al}^{30}(2008)$ from $\mathrm{Bir}$ Hospital(Nepal) reported deaths mostly due to respiratory failure and occasionally due to cardiovascular collapse. Such a situation is likely to occur quietly without the patient's deteriorating condition being noticed if there is an inadvertent stoppage of atropine infusion particularly at night in the general wards-a point of caution to be remembered ${ }^{30}$.

Statistical significance was looked for the following parameters-

a. Lag time interval-It did not show any significant relation to the mortality $\operatorname{rate}(\mathrm{p}>0.05)$. Suliman et $\mathrm{al}^{26}(2006)$ reported $4.17 \%$ mortality in those presenting $<6 \mathrm{hrs}$ and $2.79 \%$ in those presenting $>6 \mathrm{hrs}$ after inferring no significant relation.

b. Amount of OP poison intake-Increase amount of OP poison intake $(>40 \mathrm{ml})$ had significant statistical relation with increase in the mortality $\operatorname{rate}(\mathrm{p}=0.02)$. Suliman et $\mathrm{al}^{26}(2006)$ reported higher rate of mortalities $(6.3 \%)$ in those consuming $>30 \mathrm{ml}$ than those $<30 \mathrm{ml}$ (mortality being $2.7 \%$ ).

c. Severity of poisoning by POP scale had shown significant statistical correlation with increase 
S. Laudari et al, Analysis of Organophosphorus compound poisoning.

mortality rate $(p=0.04)$. Similar inferences has been described by Kara et $\mathrm{al}^{39}(2002)$ and Suliman et $\mathrm{al}^{26}(2006)$.

\section{Conclusion}

OP poisoning is more common in young females. Mortality is higher among patients with suicidal intent and in those ingesting large amount of poison $>40 \mathrm{ml}$ and having increase severity of poisoning by POP scale. Early diagnosis, vigilant/timely monitoring and prompt management in well equipped hospitals may help to reduce mortality.

It has been observed that all the patients with suicidal intent in the present study (105no.) availed OP poison very easily- $91.43 \%$ from home reserve, $5.71 \%$ from market and $2.86 \%$ from local shops. Therefore, there is an urgent need for strict implementation of the Pesticide Act which regulates the import, manufacture, sale, transport, distribution and use of pesticides with a view to prevent risk to human beings.

\section{References}

1. M. Eddleston. Patterns and problems of deliberate selfpoisoning in the developing world. $Q J$ Med 2000; 93: 715-31.

2. A.L. Jones, L. Karallidde, Poisoning, In: Davidson's Principles and Practice of Medicine, Nicholas A. Boon , Nicki R. Colledge, Brian R. Walker et al Editors, $20^{\text {th }}$ ed. , Churchill Livingstone Elsevier ; 2006, 9: 204-20.

3. W. Van der Hoek, F. Konradsen, K. Athukorala. Pesticide poisoning: a major health problem in $\mathrm{Sri}$ Lanka.Soc Sci Med 1998; 46: 495-504.

4. Christopher H Linden, Michael J Burns, Mark B. Mycyk Poisoning and drug overdosage, In: Harrison's
Principles of Internal Medicine, Dennis L. Kasper, Anthony S.Fauci, Dan L. Longo et al editors, 17th edition, The Mc Graw-Hill Companies, Inc.2008, e35:e281.

5. Senanayake, Silva and Karalliedde, A scale to assess severity in organophosphorus intoxication:POP scale.Hum Exp Toxicol,1993,12:297-9.

6. A. Srivastava, S.S. Pehsin, T. Kaleekal et al. An epidemiological study of poisoning cases reported to the National Poisons Infromation Centre, AIIMS, New Delhi. 2005;24:279-85.

7. N. Kiran, R. Shobha, V. Jai Prakash et al. Pattern of poisoning reported at South Indian Tertiary Care Hospital. IJFMC,2008;2:17-9.

8. D.P. Singh, R.P. Acharya, Pattern of poisoning cases in Bir Hospital, Journal of Institute of Medicine 2006;28:3-6.

9. F. Parikh. (Editorial). Changing trends in Poisoning. Journal of the Association of Physicians of India 2009; vol 57.

10. H.R. Yusuf, H.H. Akhter, M.H. Rahman et al. Injury related deaths amongst women aged 10-50 years in Bangladesh 1996-97, Lancet 2000; 355 :1220 - 4.

11. H. Jamil. Acute poisoning. A review of 1900 cases JPMA 1900; 40:131 - 3.

12. J. Jayaratnam. Acute pesticide poisoning. A major global health problem World Health Statistic Quart $1990 ; 43: 139-44$.

13. C. Gulohglu, I.H. Kara. Acute poisoning cases admitted to a university hospital emergency department in Diyarbakir, Turkey. Human \& experimental toxicology. 2005; 24: 49-54.

14. R.H. Ghimire, S.P. Sharma, K.R. Pandey. A Comparative Study of Acute Poisoning in Nepal at 
Journal of College of Medical Sciences-Nepal, 2011, Vol-7, No-4

Tertiary and Secondary Level Hospitals. J Nep Med Assoc. 2004; 43:130-3.

15. K.N. Ramesha, B.H. Krishnamurthy Rao, Ganesh S Kumar.Pattern and outcome of acute poisoning cases in a tertiary care hospital in Karnataka, India in IJCCM, 2009, 113:152-5.

16. N. Kiran, R. Shobha, V. Jai Prakash et al. Pattern of poisoning reported at South Indian Tertiary Care Hospital. IJFMC, 2008; 2:17-19.

17. R. Agarwal, S.P. Barthwal, D.K. Nigam et al: Changing pattern of acute poisoning in eastern UP hospital based study. J. Assoc Physic India 1995; 43: 907.

18. S.K. Dhattarwal, S.S. Dalal: Profile of deaths due to poisoning in Rohtak Haryana in the 154 year 1995; Journ Forensic Med Toxicol 1997;14:51.

19. N. Senanayake, H. Petris: Mortality due to poisoning in a developing and agricultural country: Trends over 20 years, Hum Exp. Toxicology 1995;14: 808-11.

20. Anjum, Khan and Mubarik et al. Profile of poisoning cases in Jawaharlal Nehru Medical College Amu Aligarh. JAPI 2009;57.

21. S.B. Khadka, S.B. Ale, A study of poisoning cases in emergency Kathmandu Medical College Teaching Hospital, KUMJ, 2005; 3: 388-91.

22. P. Karki; S.G. Hansdak; S. Bhandari; Aclinicoepidemiological study of organophosphorus poisoning at a rural based teaching hospital of eastern Nepal Tropical doctor, 2001;31:32-4.

23. C.H. Srinivas Rao, V. Venkateswarlu, T. Surender et al. Insecticide poisoning in south India — opportunities for prevention and improved medical management. Trop Med Int Health. 2005; 10:581-8.
24. Siwach and Gupta. The profile of acute poisoning in Haryana-Rohtak Study. JAPI 1995;43:756-9.

25. Rahman H Habibur, Samad Md Abdus. An epidemiological study of acute poisoning in arural hospital of Bangladesh. JOPSOM 2000;19:40-46.

26. M.I. Suliman, R. Jibran, M. Rai. The analysis of organophosphates poisoning cases treated at Bahawal Victoria Hospital, Bahawalpur in 2000-2003. Pakistan Journal of Medical Sciences. 2006;22:244-9.

27. L.B. De Alwis, "Agrochemical poisoning in Sri Lanka", Forensic Science International, 1988; 36: 81-9.

28. S.R. Thapa, P. Lama, N. Karki et al. Pattern of poisoning cases in Emergency Department of Kathmandu Medical College Teaching Hospital, Kathmandu University Medical Journal, 2008, 6:209-13.

29. S.B. Marahatta, J. Singh, R. Shrestha et al, Poisoning cases attending emergency department in Dhulikhel Hospital- Kathmandu University Teaching Hospital, KUMJ,2009;7:152-6.

30. S. Rehiman, S.P. Lohani and Bhattrai. Correlation of serum cholinesterase level, clinical score at presentation and severity of organophosphorus poisoning. JNMA 2008;47:47-52.

31. J.M. Shaikh, F.G. Siddiqui and A.G. Soomro. Management of acute organophosphorus insecticide poisoning: An experience at a university hospital. 2008:97-101.

32. R.S. Wadia, C. Sadagapam, R.M. Amin et al. Neurological manifestation of organophosphorus insecticide poisoning.J Neural Neurosurg Psychia 1974;37:841-7.

33. G. Avasthi, G. Singh. Serial neuro-electrophysiological studies in acute organophosphate poisoning:correlation with clinical findings, serum 
S. Laudari et al, Analysis of Organophosphorus compound poisoning.

cholinesterase levels and atropine dosages. J Assoc Physicians India 2000;48:794-9.

34. Jayawardane,Dawson, Weerasinghe,Karalliedde et al. The spectrum of intermediate syndrome following acute organophosphorus poisoning: A prospective cohort study from Sri Lanka.PLOS medicine 2008;5:e147.

35. M. Eddleston, L. Szinicz, P. Eyer, et al. Oximes in acute organophosphorus pesticide poisoning: a systematic review of clinical trials. $Q J$ Med 2002; 95:275-83.

36. L. Karalliedde, N. Senanayake,"organophosphorus poisoning", Br.Jr. Anesthesia. 1989; 63:736-50.
37. S.K. Gupta, M.P. Joshi, Pesticide poisoning cases attending five major hospitals of Nepal, JNMA, 2002, 41:447-56.

38. R. Goswamy, A. Chaudhari A.A. Mahashur. Study of respiratory failure in organophosphate and carbamate poisoning. Heart Lung 1994;23:466-72.

39. I.H. Kara, C. Guloglu, A. Karabulut et al. Sociodemographic, clinical and laboratory features of cases of organophosphorus intoxication who attended the emergency department in Southeast Anatolian Region of Turkey. Environ Res 2002; 88:82-8. 